\title{
A Study of Lexical Cohesion Theory in Reading Comprehension
}

\author{
Qingshun $\mathrm{He}^{1}$ \\ ${ }^{1}$ Faculty of English Language and Culture, Guangdong University of Foreign Studies, Guangzhou, China \\ Correspondence: Qingshun He, North 2, Baiyun Avenue, Baiyun District, Guangzhou City, Guangdong, 510420, \\ China. Tel: 86-158-0002-9026. E-mail: markman1998@163.com
}

Received: July 29, 2014 Accepted: October 22, 2014 Online Published: November 25, 2014

doi:10.5539/ijel.v4n6p143 URL: http://dx.doi.org/10.5539/ijel.v4n6p143

\begin{abstract}
This paper aims to introduce students to a new problem-solving method in reading comprehension through analyzing the feasibility of using the lexical cohesion theory based on Systemic Functional Linguistics. For this purpose, an empirical research was carried out to some Chinese college students. Research shows that the lexical cohesion theory can help improve students' reading speed and accuracy and thus provide them with a new problem-solving method in reading comprehension. The implications of the lexical cohesion theory to reading comprehension can be reflected at such language levels as lexis, sentence and text. But this kind of improvement is limited to a certain extent. The students' reading skills depend mainly on their language proficiency, and reading techniques can only play a supporting role.
\end{abstract}

Keywords: lexical cohesion, repetition link; information point, reading comprehension

\section{Introduction}

Reading as a means of language input plays an important role in second language acquisition. For decades, extensive and in-depth researches on reading have been carried out from such perspectives as psycholinguistics, sociolinguistics, applied linguistics and cognitive psychology, etc. with fruitful achievements. In recent years, more and more researchers have begun to introduce textual linguistics into language teaching (Yue, 1993; Liu, 1999). The focus of research of textual linguistics is on the cohesion and coherence of text. Cohesion is one of the three systems (Theme-Rheme system, Cohesion system and Information system) of the textual metafunction in Systemic Functional Linguistics (Halliday, 1985, 1994; Halliday \& Matthiessen, 2004, 2014). "The concept of cohesion is a semantic one" (Halliday \& Hasan, 1976, p. 4); it refers to the mutual interpretation of two language components in the text (Halliday \& Hasan, 1976; Brown \& Yule, 1983; Hu et al., 1989; Hoey, 1991; Zhu et al., 2001).

Halliday \& Hasan (1976) distinguish five cohesive devices: reference, substitution, ellipsis, conjunction and lexical cohesion. The first four are grammatical devices, and the last, lexical. Lexical cohesion refers to a number of semantically related words occurring in text subsequently to make all parts of the text connect closely to each other in meaning (Zheng, 2002). Lexical cohesion devices include reiteration and collocation. Reiteration is further divided into full and partial repetitions. Full repetition means that two lexical items are same in both form and meaning, and partial repetition, two lexical items different in form but having certain similar semantic features, including synonymy, antonymy, hyponymy, meronymy and general nouns. Collocation refers to the co-occurrence of lexical items. Hoey (1991) develops the lexical repetition pattern in the Hallidayan sense into simple repetition, complex repetition, simple paraphrase, complex paraphrase, superordinate, hyponymy, co-reference, substitution and ellipsis, etc. According to Hoey $(1991 ; 1994 ; 1995)$, simple lexical repetition occurs when a lexical item that has already occurred in a text is repeated with no greater alternation than is entirely explicable in terms of a closed grammatical paradigm. This is the most basic repetition pattern. Complex repetition occurs either when two lexical items share a lexical morpheme but are not formally identical, or when they are formally identical but have different grammatical functions. Simple paraphrase occurs whenever a lexical item may substitute for another in context without loss or gain in specificity and with no discernible change in meaning. Hoey's (1991) simple paraphrase is quite the same as Halliday \& Hasan's (1976) synonymy and near-synonymy. If the interpretation of one of two words with no shared morphemes is dependent on that of the other, they are complex paraphrase of each other. For example, "writer" and "writing" are complex repetition because they both share the morpheme "write", and "writing" and "author" are complex paraphrase because each of the two can be explained through the other. 
Hoey's (1991) repetition pattern includes also such grammatical cohesive devices as reference, substitution and ellipsis in the Hallidayan sense. He refers to them as textual items, which are members of the closed system. They have no specific meanings themselves. The meanings they refer to depend on those of other items in context, so they are grammatical rather than lexical items. On the other hand, they do function as repetition of the lexical items occurred in text to make the text cohesive. Therefore, Hoey (1991) gives them a special status in text analysis. They are treated as if they were lexical, and thus, on the second and subsequent occurrence, are analyzed as entering into lexical links.

Repetition plays an important part in the construction of text. Using relevant repetition devices, a paragraph can be integrated into a text coherent in meaning. For example:

[1] (1) Liberty, then, is not license. (2) License is the opportunity to act regardless of other people; (3) liberty is the opportunity to act in such a way as not to interfere with the opportunity of others. (4) When license increases, (5) liberty decreases.

There are five clauses in [1]. The thematic progress can be shown as:

$\begin{array}{ll}\mathrm{T} 1 \quad \rightarrow & \mathrm{R} 1 \\ \downarrow & \downarrow \\ \mathrm{T} 3 \rightarrow \mathrm{R} 3 & \mathrm{~T} 2 \rightarrow \mathrm{R} 2 \\ \downarrow & \downarrow \\ \mathrm{T} 5 \rightarrow \mathrm{R} 5 & \mathrm{~T} 4 \rightarrow \mathrm{R} 4\end{array}$

$\mathrm{T} 2$ and $\mathrm{T} 4$ are the simple repetition of R1, and T3 and T5 that of T1, hence are Given information. And "liberty" and "license" are antonyms, so the Rhemes of the clauses with "liberty" and "license" as Themes respectively are also antonymous in meaning. Therefore, "the opportunity to act regardless of other people" is antonymous with "the opportunity to act in such a way as not to interfere with the opportunity of others", and "increase" and "decrease" are antonyms. That is:

$\mathrm{R} 2 \rightarrow \mathrm{R} 3$

$\mathrm{R} 4 \rightarrow \mathrm{R} 5$

Through this kind of lexical repetition, [1] becomes a coherent text in meaning. Halliday and Hasan (1976) have been most severely criticized over the years because they insist on seeing cohesion as a necessary property for the creation of unity in text. (e.g., de Beaugrande \& Dressler, 1980; Brown \& Yule, 1983; Ellis, 1992; Enkvist, 1978; Hellman, 1995; Lundquist, 1985; Sanford \& Moxey, 1995). It is maintained that "overt markers of cohesion were not enough to make a text connected" (Tanskanen, 2006, p. 16), and the propositions realized by clauses should be logico-semantically coherent. Coherence is fundamental to reading comprehension (Widdowson, 1978). The question is what kind of language fragments can constitute a coherent text. Hoey (1991) assumes that in non-narrative texts any two sentences are connected as packages of information if they share at least three points of reference. The reason is very clear. If two sentences sharing less than three points of reference were treated as being a significant connection, then nearly every sentence would be connected to every other. That is to say, two sentences can establish a significant connection, or repetition link, only when there are at least three connection points of repetition. If sentences are considered as interrelated information packages, those closely related to the development of the text will have more repetition links with other sentences. This is why Hoey (1991) refers this kind of sentences as central sentences. Those contributing little to the topic development have fewer repetition links, hence are referred to as marginal sentences. Marginal sentences carry less information, or in other words, the information they carry are not directly necessary or functions little to the text development.

Since repetitions are important in the construction of text, they must be also important in the understanding to the text. Based on relevant theories on repetition as a cohesion device, this research intends to investigate the feasibility of lexical cohesion devices in reading comprehension of language learners. For this purpose, we will first carry out an empirical research on the influence and impact of lexical cohesions on the Chinese students' reading comprehension of English texts in Section 2. The influence will be tested from two aspects: reading speed and reading accuracy. Section 3 is a discussion on the research result. The implications of the lexical cohesion theory on reading comprehension from such language levels as lexis, sentence and text are provided in Section 4. 


\section{Research Design}

\subsection{Subjects for Research}

The subjects for research in this experiment are 107 non-English major college students. These students are from two parallel classes, one being taken as the experimental group, and the other, the control group. The two groups of students are balanced in sex and English proficiency (good, medium and poor). Before the experiment, the average English test scores of the two groups of students are fairly equal (67.4 in the experimental group and 68.7 in the control group respectively).

\subsection{Variables}

The independent variables in this experiment are the training methods for answering the questions of the reading comprehension examinations. The students in the experimental group are trained to answer questions according to the lexical cohesion theory acquired from the teacher, and the students in the control group are trained according to the traditional method (or according to their own habit of answering questions). The scores of the students' after experiment test are taken as the dependent variables.

\subsection{Experiment Materials}

In order to ensure the objectivity and impartiality of the experiment, the teaching materials we use are the original reading comprehension part of the CET-4 test papers and the reading comprehension part of the supporting exercises of the college English textbooks.

\subsection{Experiment Procedure}

\subsubsection{Before Experiment Test}

The before experiment test aims to make a comparison in the reading abilities and the achievements between the two groups of students in reading comprehension. The test paper consists of four reading materials (This is in agreement with the CET-4). The students are required to finish the test within 30 minutes (The time limit of reading comprehension section of the CET-4 is 35 minutes). After the test, the teacher interviews the students. Most students would read the reading materials first and then answer the questions.

The variance analysis of results of the before experiment test shows that the scores of the two groups have no significant difference $(\mathrm{p}=0.964>0.05)$. We can conclude that the two groups are at the same level in English reading comprehension. The analysis of the test papers also shows that most of the students could not finish the questions within 30 minutes, especially those students with good command of English because most of them left the last passage untouched or roughly answered and the first two or three passages obviously carefully dealt with. Most of the poor students, however, have finished the questions, but fairly roughly.

\subsubsection{Teaching}

The students in the experimental group are trained with the lexical cohesion theory. There is no reading comprehension training during the teaching process. Rather, they are taught the three systems of the textual metafunction, especially the use of lexical repetition devices. The purpose of this teaching is to give the subjects for experiment a general impression on textual cohesion and coherence.

The teacher revised the repetition patterns in teaching in order to fulfill the requirement for answering the questions of reading comprehension. The function of lexical repetition in text is to connect the relevant sentences in the text. However, reading comprehension tests does not require the connection in form but the repetition in meaning. The answer choice to a question is in total equivalence with the relevant sentence in the text. Or in other words, the information carried by the answer choice should be totally included in the information of the relevant sentence in the text. In analyzing lexical repetitions in text, Hoey (1991) also makes the same point. Taking bear and animal as an example, Hoey (1991) holds that if bear occurs before animal, they form a repetition link, but not vice versa. This is because bear contains the information of animal. Therefore, it is necessary to revise the lexical repetition into the repetition of information points. The unit of the information point is dynamic rather than static. If all the information points in an answer choice are included in the relevant sentence in the text, this choice is the correct answer.

In the mean time, the students in the control group receive traditional normal English teaching. In the following 16 weeks, the students in both the experimental and the control groups are trained with the reading materials in the supporting exercises of the textbooks. The students in the experimental group are encouraged to use the lexical cohesion theory for them to better understand and apply the theory, while the students in the control group adopt the traditional way to practice. 


\subsubsection{After Experiment Test}

After sixteen weeks, the two groups of students are tested again. The test scores are analyzed using the statistic software SPSS. Table 1 shows the average scores and the standard deviations before and after the experiment.

Table 1. Test scores before and after experiment

\begin{tabular}{llll}
\hline \multirow{2}{*}{ Group } & Test & Before & After \\
& & & \\
\multirow{2}{*}{ Experimental } & Average & 5.33 & 7.43 \\
& SD & 2.10 & 2.68 \\
\hline \multirow{2}{*}{ Control } & Average & 5.59 & 7.16 \\
& SD & 2.25 & 2.48 \\
\hline
\end{tabular}

One-Way ANOVA test shows that the scores of both the experimental and the control groups after the experiment are obviously higher $(\mathrm{p}<0.05)$ than those before the experiment. That is to say that the average difference of both the two groups between the before and after experiment is significant at the level of 0.05 , but only the average difference of the experimental group is significant at the 0.001 level, and that of the control group has not reached the significant level of difference $(\mathrm{p}=0.026)$.

\section{Result Analysis}

Because the subjects for research have not reached the required CET-4 level in English reading, many of them cannot understand the content of the reading materials. As can be seen from the test paper, most of the good students in the control group did not finish the reading within the required time limit, but their finished answers are at a higher rate of correctness. This means that good students are pursuing accuracy and correctness in answering the questions. In the mean time, most of the poor students finished the questions but at a lower rate of correctness. The students in the experimental group, however, finished all the questions in the required time limit, but the rate of correctness of the good students in this group is not significantly higher than that of those in the control group. The rate of correctness of the poor students in the experimental group, however, is significantly higher than that of the poor students in the control group. What's more, the poor students all left obvious traces of reading in the test paper.

The experimental result shows that under the condition that the students can understand the reading materials careful reading can ensure the accuracy of the answers. Due to the limitation of time, good students in the control group all chose to read carefully to give up the reading speed, and those good students in the experimental group adopted a top-down reading method by applying the lexical cohesion theory, which ensures both the accuracy and the speed of reading. For the poor students, the lexical cohesion theory has undoubtedly given them a breakthrough into the text.

In reading comprehension test, the students should first check the questions using the lexical cohesion theory, find the corresponding sentence in the text, and then determine the correct answer. However, for those of lower English proficiency, it is not always easy to identify the corresponding sentence in the text, especially when there are relatively fewer simple repetitions. Therefore, as a technique for answering questions, the lexical repetition theory cannot play an unlimited role in reading comprehension. The students' performance will mainly depend on their language level, and the reading techniques can play only a supporting role. On the other hand, the lexical cohesion theory can give inspiration to the teaching of reading, even the teaching of vocabulary and writing.

\section{Implications to Reading Comprehension}

Since the language proficiency is the decisive factor affecting students' achievements, we can try to apply the lexical cohesion theory to the training of the students' reading ability. The more repeated information points in two sentences of the same text, the closer their relations. The sentence which has the most repeated information points with other sentences can be taken as the topic sentence. In specific reading teaching, the teacher can take a top-down method to guide the students to find the keywords in the text and choose the sentence with the most keywords as the topic control sentence, and then find all the sentences having higher relevance with this sentence. These sentences together can be able to realize the main idea of the text (Hoey, 1991; Liu, 1999). The top-down pattern of reading mainly emphasizes the function of cognitive schemata in reading comprehension, which considers reading as a process of selecting, predicting, checking and testing. The bottom-up pattern, however, mainly emphasizes the function of the text itself, considering reading as a process from the decoding of words to 
the obtaining of the information. Careful reading usually prefers the bottom-up pattern to ensure the accuracy of reading comprehension, and speed reading prefers the top-down pattern to ensure reading speed. However, emphasizing only the accuracy but neglecting the speed will result in the lower efficiency; and on the other hand, emphasizing only the speed but neglecting the accuracy will handicap the access to the information. Therefore, a successful reader should be able to deal with the relationship between careful reading and speed reading, that is, to get accurate information and to guarantee the reading speed as well. In language teaching, careful reading is generally used, but in reading comprehension tests, speed reading is preferred. The lexical cohesion theory provides an effective problem-solving method, because in speed reading the reader should select the sentences to be processed (Liu, 1999). Obviously, the lexical cohesion theory helps find the relevant sentences in text. The two linked sentences must have some shared information. In reading training, the teacher should take a top-down model to guide the students to find relevant sentences in text and determine the correct answer. In the following, we will analyze the application of the lexical cohesion theory in reading comprehension tests from such language levels as lexis, syntax and text.

\subsection{Lexical Level}

The examination questions at the lexical level usually require the subjects to explain an unfamiliar word, and the explanation to the word is usually in the context in the form of synonyms or antonyms, as in example [2]. Even if the explanation is not offered, it can be inferred from the context, as in example [3]:

[2] Also, parents should realize that "example is better than precept". If they are not sincere and do not practice what they preach, their children may grow confused, and emotionally insecure when they grow old enough to think for themselves, and realize they have been to some extent fooled. (CET-4, 1998)

Question: The word "precept" probably means "
A. idea
B. punishment
C. behaviour
D. instruction

It can be seen from the structure of the clause "example is better than precept" that "precept" and "example" are antonyms. In the four choices, only D contains the meaning of "teaching", hence the correct answer.

[3] Non-smokers remembered 19 percent more of the most important information than active smokers, and deprived smokers bested those who had smoked a cigarette just before testing. (CET-4, 1998)

Question: The word "bested" most probably means
A. beat
B. envied
C. caught up with
D. made the best of

It can be seen in [3] that test shows that deprived smokers perform better than those who smoke a cigarette before the test. In the four choices, only "beat" can express of the meaning of "bested".

In addition, there is also an explanation to a word not in the form of synonyms or antonyms occurring in the text but by a relevant sentence in the text. For this kind of questions, the lexical cohesion theory is undoubtedly a good solution. For example:

[4] Perfectionists struggle over little things at the cost of something larger they work toward. "To keep from losing the forest for the trees," says Charles Garfield, associate professor at the University of California, San Francisco, "we must constantly ask ourselves how the details we're working on fit into the larger picture. (CET-4, 1995)

Question: The word "perfectionists" refers to those who

A. demand others to get everything absolutely right

B. know how to adjust their goals according to the circumstances

C. pay too much attention to details only to lose their major objectives

D. are capable of achieving perfect results in whatever they do

Although choices A, B and D are relevant with "perfectionist" in meaning, they have no repeated information points with the relevant sentence in the text, hence they are not linked. The "pay too much attention to" is the semantic repetition of "struggle over" in the text, "details" and "little things form a complex repetition, "only to lose" is the paraphrase of "at the cost of", and "their major objectives" is the paraphrase of "something larger they work toward". All the information points can be found in the relevant sentence in the text, so choice C is the correct answer. It can also be seen that in answering this question, the students do not need to know the word "perfectionist" at all. 


\subsection{Sentential Level}

The examination questions at the sentential level usually require the subjects to explain a sentence or a part of a sentence. See example [5]:

[5] More than 30,000 drivers and front seat passengers are killed or seriously injured each year. At a speed of only 30 miles per hour it is the same as falling from a third-floor window. Wearing a seat belt saves lives; it reduces your chance of death or serious injury by more than half. (CET-4, 1989)

Question: Wearing a seat belt in a vehicle

A. reduces road accidents by more than half

B. Saves lives while driving at a speed up to 30 miles per hour

C. Reduces the death rate in traffic accidents

D. Saves more than 15,000 lives each year

It is very easy to find the corresponding sentence in the text. The subjects should check which of the four choices is equivalent in meaning with "save lives, it reduces your chance of death or serious injury by more than half". Choice A has two cohesion links with the corresponding sentence, i.e., "reduces" and "by more than half", both are simple repetitions, but "road accidents" has no equivalent in the corresponding sentence in the text. This is to say that choice A provides more information than the corresponding sentence in the text. Choice B has only one lexical cohesion link with the corresponding sentence, the rest being redundant information. Choice $\mathrm{D}$ has also only one lexical cohesion link "save lives". The "death rate" in choice C is the semantic repetition of "chance of death" in the corresponding sentence. All the information points in choice $\mathrm{C}$ are included in the corresponding sentence in the text, and hence choice $\mathrm{C}$ is the correct answer.

In the same text, there is such a sentence as example [6]:

[6] It will not be up to the driver to make sure you wear your belt. But it will be the driver's responsibility to make sure that children under 14 do not ride in the front unless they are wearing a seat belt of some kind. (CET-4, 1989)

Question: It is the driver's responsibility to

A. make the front seat passenger wear a seat belt

B. make the front seat children under 14 wear a seat belt

C. stop children riding in the front seat

D. wear a seat belt each time he drives

With the same method of analysis, all the information points in choice B can be included in the corresponding sentence in the text. Hence choice B is the correct answer. It can be concluded that in the correct answer, there should be no extra information not included in the corresponding sentence in the text. Or in other words, all the information points have their equivalents in the corresponding sentence in the text.

\subsection{Textual Level}

The purpose of the examination questions at the textual level is to check the subjects' understanding to the whole text. This is a relatively complex process, but by means of the lexical cohesion theory this process will become much easier. For example:

[7] (1)A good modern newspaper is an extraordinary piece of reading. (2)It is remarkable first for what it contains: the range of news from local crime to international politics, from sport to business to fashion to science, and the range of comment and special features as well, from editorial page to feature articles and interviews to criticism of books, art, theatre and music. (3)A newspaper is even more remarkable for the way one reads it: never completely, never straight through, but always by jumping from here to there, in and out glancing at one piece, reading another article all the way through, reading just a few paragraphs of the next. (4)A good modern newspaper offers a variety to attract many different readers, but far more than any one reader is interested in. (5)What brings this variety together in one place is its topicality, its immediate relation to what is happening in your world and your locality now. (6)But immediacy and the speed of production that goes with it mean also that much of what appears in a newspaper has no more than transient value. (7)For all these reasons, no two people really read the same paper: what each person does is to put together out of the pages of that day's paper, his own selection and sequence, his own newspaper. (8)For all these reasons, reading newspapers efficiently, which means getting what you want from them without missing things you need but without wasting time, demands 
skill and self-awareness as you modify and apply the techniques of reading. (CET-4: 1998)

Question: The best title for this passage would be " ".

A. The importance of Newspaper Topicality

B. The Characteristics of a Good Newspaper

C. The Variety of a Good Newspaper

D. Some Suggestions on How to Read a Newspaper

The thematic progress can be shown as:

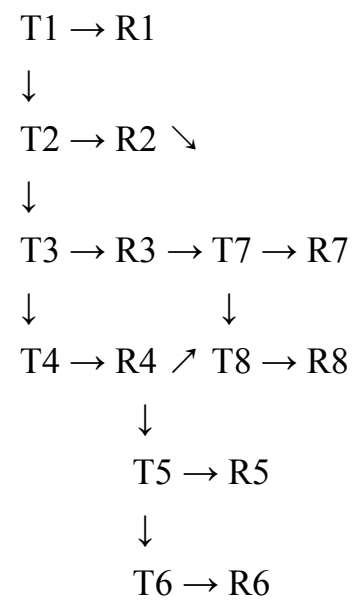

T1, T2, T3 and T4 constitute a lexical cohesion chain: "A good modern newspaper" - "it" - "a newspaper" - "A good modern newspaper". They introduce respectively the following information points: "an extraordinary piece of reading", "remarkable first for what it contains", "even more remarkable for the way one reads it", "offers a variety to attract many different readers". These New information points explain the specific characteristics of a good newspaper from different aspects. Therefore, the title of this text should be "The Characteristics of a Good Newspaper", and hence choice B is the correct answer.

\section{Conclusion}

Lexical cohesion theory can be helpful for reading comprehension. Under the condition that the students are at the same language level, the lexical cohesion theory is effective for the accuracy and speed in reading comprehension examinations. In training the students in reading comprehension, the teacher should consciously help the students to use the lexical cohesion theory to find keywords, to constitute repetition links, to grasp the main ideas and to obtain textual information as much as possible. However, this effect is limited. This is because reading ability is after all only a reflection of the language proficiency. It is not appropriate to equate reading skills to language skills. The purpose of reading comprehension is to check the students' language proficiency. Therefore, in the training of reading comprehension, the focus should be on the training of the basic language skills, and reading techniques can only play a supporting role.

\section{References}

Brown, G., \& Yule, G. (1983). Discourse Analysis. London: Cambridge University Press. http://dx.doi.org/10.1017/CBO9780511805226

de Beaugrande, R., \& Dressler, W. (1981). Introduction to Text Linguistics. London \& New York: Longman.

Ellis, D. G. (1992). From Language to Communication. Hillsdale, NJ: Erlbaum.

Enkvist, N. E. (1978). Coherence, pseudo-coherence, and non-coherence. In J. O. Östman (Ed.), Cohesion and Semantics (pp. 109-128). Åbo: Meddelanden från Stiftelsens för Åbo Akademi Forskningsinstitut.

Halliday, M. A. K. (1985). An Introduction to Functional Grammar. London: Edward Arnold.

Halliday, M. A. K. (1994). An Introduction to Functional Grammar (2nd ed.). London: Edward Arnold.

Halliday, M. A. K., \& Hasan, R. (1976). Cohesion in English. London \& New York: Longman Group.

Halliday, M. A. K., \& Matthiessen, C. M. I. M. (2004). An Introduction to Functional Grammar (3rd ed.). London: Edward Arnold. 
Halliday, M. A. K., \& Matthiessen, C. M. I. M. (2014). Halliday's Introduction to Functional Grammar (4th ed.). London \& New York: Routledge.

Hellman, C. (1995). The notion of coherence in discourse. In G. Rickheit, \& C. Habel (Eds.), Focus and Coherence in Discourse Processing (pp. 190-202). Berlin \& New York: de Gruyter.

Hoey, M. (1991). Patterns of Lexis in Text. Oxford: Oxford University Press.

Hoey, M. (1994). Patterns of lexis in narrative: A preliminary study. In S. K. Tanskanen \& B. Wårvik (Eds.), Topics and Comments: Papers from the Discourse Project [Anglicana Turkuensia 13] (pp. 1-40). Turku: University of Turku.

Hoey, M. (1995). The lexical nature of intertextuality: A preliminary study. In B. Wårvik, S. K. Tanskanen \& R. Hiltunen (Eds.), Organization in Discourse: Proceedings from the Turku Conference [Anglicana Turkuensia 14] (pp. 73 - 94). Turku: University of Turku.

Hu, Z. L., Zhu, Y. S., \& Zhang, D. L. (1989). A Survey of Systemic Functional Grammar. Changsha: Hunan Education Publishing House.

Liu, C. D. (1999). Text Linguistics for Teachers. Shanghai: Shanghai Foreign Language Education Press.

Lundquist, L. (1985). Coherence: From structures to processes. In E. Sözer (Ed.), Text Connexity, Text Coherence: Aspects, Methods, Results (pp. 151-175). Hamburg: Helmut Buske.

Sanford, A. J., \& Moxey, L. M. (1995). Aspects of coherence in written language: A psychological perspective. In M. A. Gernsbacher \& T. Givón (Eds.), Coherence in Spontaneous Text (pp. 161-187). Amsterdam \& Philadelphia: John Benjamins. http://dx.doi.org/10.1075/tsl.31.07san

Tanskanen, S. K. (2006). Collaborating towards Coherence. Amsterdam \& Philadelphia: John Benjamins. http://dx.doi.org/10.1075/pbns.146

Widdowson, H. G. (1978). Teaching Language as Communication. Oxford: Oxford University Press.

Yue, M. Y. (1993). Cohesion and the teaching of EFL reading. In Y. Zhu (Ed.). Language, Text and Context. Beijing: Tsinghua University Press.

Zheng, G. Y. (2002). Chinese Textual Linguistics. Beijing: Foreign Languages Press.

Zhu, Y. S., Zheng, L. X., \& Miao, X. W. (2001). A Contrastive Study of Cohesion in English and Chinese. Shanghai: Shanghai Foreign Language Education Press.

\section{Copyrights}

Copyright for this article is retained by the author(s), with first publication rights granted to the journal.

This is an open-access article distributed under the terms and conditions of the Creative Commons Attribution license (http://creativecommons.org/licenses/by/3.0/). 